\title{
Experimental Study, Characterization and Performance Test of Epoxy Cyclohexane-Based Transparent Polyurethane Material
}

\author{
Xuemei WANG ${ }^{1}$, Xiang GUI ${ }^{1}$, Yingping $\mathrm{QI}^{2}$, Yongfeng $\mathrm{SHEN}^{2}$, Hua $\mathrm{LI}^{1 *}$ \\ ${ }^{1}$ School of Chemical and Energy Engineering, Zhengzhou University, No. 100 Science Road, Zhengzhou, Henan, China \\ ${ }^{2}$ Zhengzhou Museum, No. 168 Songshan South Road, Zhengzhou, Henan, China \\ crossref http://dx.doi.org/10.5755/j02.ms.22858
}

Received 01 March 2019; accepted 06 May 2019

\begin{abstract}
A novel epoxy cyclohexane-based polyurethane material was synthesized from a self-made epoxy cyclohexanetetrahydrofuran (CHO-THF) co-polyether. Due to the special rigid six-membered ring skeleton in the polyether molecular chain, the polyurethane materials have excellent mechanical properties, good optical transparency and weather resistance. In this paper, the synthesis process of the epoxy cyclohexane-based polyurethane material was studied and the properties of the material were tested. The results showed that curing parameters $\mathrm{R}$ value had effects on the mechanical properties and optical transparency of the material.

Keywords: CHO-THF co-polyether, transparent polyurethane, optical transparency, mechanical properties.
\end{abstract}

\section{INTRODUCTION}

Polyurethane is a polymer containing carbamate group (-NHCOO-) in its molecular structure, which is formed in a reaction between monomers that contain at least two hydroxyl $(-\mathrm{OH})$ groups and other monomers that contain at least two isocyanate $(-\mathrm{N}=\mathrm{C}=\mathrm{O})$ functional groups [1]. Ordinary polyurethane materials suffer from some serious application drawbacks, including low optical transparency, insufficient impact resistance, low resistance to open flames and high temperatures $[2,3]$. However, transparent polyurethane has wider applications in several high-tech areas such as laminated windshield glass of aircraft and high-speed rail due to the transparent property and good performance in impact resistance and outstanding low temperature performance, which is a new direction in the development of polyurethane industry in recent years [4].

The factors that influence the transparency of PU materials are composition (e.g., the structure of diisocyanate), the type and molecular weight of the soft segment, crystallinity, and hydrogen bonding (intermolecular interactions) [5]. Polyester polyurethane (PU) is easy to crystallize due to the high polarity of ester group $(-\mathrm{C}=\mathrm{O}-)$ in its molecular structure, thus light transmittance is lowered [6]. However, the intermolecular chain force of polyether polyurethane is much smaller than that of polyester polyurethane, which is not easy to crystallize and has high transparency [7].

In this paper, epoxy cyclohexane-tetrahydrofuran (CHO-THF) transparent polyurethane material (TPU) was synthesized by means of pre-polymer reaction method using self-made co-polyether of cyclohexane oxidetetrahydrofuran (CHO-THF). Here, we report a novel synthetic routes and processes to produce PU materials of improved properties, in attempts to strengthen the application performance of transparent PU materials.

\section{EXPERIMENTAL SECTION}

\subsection{Materials and instruments}

Isophorone diisocyanate (IPDI), CHO-THF copolyether and methacrylic acid- $\beta$-hydroxyethyl ester (HEMA) were used as raw materials; dibutyltin dilaurate (DBTL) was selected as catalyst and azobisisobutyronitrile (AIBN) was used as curing crosslinking agent. All other reagents were analytical grade provided by Tianjin Kemiou Chemical Reagent Co., Ltd.

The following equipment and instruments were used: Constant Temperature Water Bath, DF-101S, Henan Baize Instrument Co., Ltd.; Analytical Balance, AV II -400, Metler-Toledo Instruments Co.; Differential ThermalDSC-TGA, DTG-60, Shimadzu Corporation, Japan; Shaw hardness tester, LX-A, Shanghai Precision Scientific Instruments Co., Ltd.; Cantilever Beam Notch Impact Testing Machine, XJU-22, Chengde City Testing Machine Factory; Electronic Universal Material Testing Machine, INSTRON 1185; A Fourier infrared spectrometer, FTIR200, Thermo Corporation of the United States; Nuclear magnetic resonance instrument (NMR), INOVA-400, Bruker Corporation of the United States.

\subsection{Preparation}

The process is divided into two steps: (1) Self-made CHO-THF co-polyether: The copolymerization of CHO and THF was achieved at $0{ }^{\circ} \mathrm{C}$ using $\mathrm{BF}_{3}$. $\mathrm{OEt}_{2}$ as catalyst and glycerol as chain extender. The molar ratio of THF to $\mathrm{CHO}$ was $1: 2$, that of $\mathrm{BF}_{3} . \mathrm{OEt}_{2}$ to $\mathrm{CHO}$ was $0.045: 1$, and that of glycerol to $\mathrm{CHO}$ was $0.01: 1$. After $5.5 \mathrm{~h}$, a new kind of transparent light-yellow viscous liquid with yield of $98.0 \%$ and number average molecular weight of 4295 was obtained. (2) Preparation of TPU: In this experiment, the molar ratio of IPDI, CHO-THF co-polyether and HEMA

\footnotetext{
* Corresponding author. Tel.: 0086-371-67781801;

fax: 0086-371-63886154. E-mail address: lihua@zzu.edu.cn (H. Li)
} 
was set to $3: 1: 3$. IPDI, CHO-THF and DBTL were added under the condition of $\mathrm{N}_{2}$ protection, stirring constantly at the $80-90{ }^{\circ} \mathrm{C}$ for $1 \mathrm{~h}$, then some HEMA was added with continuous stirring at $70-80{ }^{\circ} \mathrm{C}$ for $50 \mathrm{~min}$. Finally, TPU was obtained by adding AIBN to at a certain temperature.

\subsection{Determination of NCO content and hydroxyl number}

Determination of hydroxyl number: $0.5 \mathrm{~g}$ sample was got and added in $20 \mathrm{~mL}$ toluene, stirring to completely dissolve, then $10 \mathrm{~mL}$ of $1 \mathrm{~mol} / \mathrm{L}$ Dibutylamine-Toluene Mixture was added and mixed at room temperature. Another $50 \mathrm{~mL}$ of isopropanol and a few drops of Bromcresol green indicator were added, and titrated with a standard $\mathrm{HCl}$ solution, at the same time, a blank test was performed, which was observed that the liquid changed from blue to yellow as the reaction end point. The NCO content can be calculated by the following formula:

$\mathrm{NCO} \%=\frac{\left(V_{1}-V_{2}\right) \times C \times 42.02}{m \times 1000} \times 100 \%$.

Among them, $V_{1}$ is the volume of $\mathrm{HCl}$ standard solution required for titration blank test, $\mathrm{ml} ; V_{2}$ is the volume of $\mathrm{HCl}$ standard solution consumed by sample, $\mathrm{ml} ; C$ : $\mathrm{HCl}$ standard solution concentration, mol/L; 42.02:-NCO group relative molar mass, $\mathrm{g} / \mathrm{mol} ; M$ is the sample quality, $\mathrm{g}$.

Determination of hydroxyl number [8]: hydroxyl number was determined according to national standard GB/T 12008-1989.

\subsection{Performance test}

Hardness and tensile properties were tested according to national standard [9] GB/T 2411-2008 and national standard [10] GB/T 1040.1-2006. Impact strength was tested according to national standard [11] GB/T 1843-2008.

Optical performance test: the light transmittance of the material was measured by UV-260 ultraviolet-visible diffuse reflectometer, whose test conditions were as follows: the temperature was $23 \pm 2{ }^{\circ} \mathrm{C}$, the sample size was $50 \times 50 \times 1 \mathrm{~mm}$, and the relative humidity was $50.5 \%$.

\section{RESULTS AND DISCUSSION}

\subsection{Experimental principle}

The reaction process of preparing PUA with CHO-THF and IPDI, HEMA, etc. is shown in Fig. 1.

The epoxy cyclohexyl transparent polyurethane (TPU) with higher molecular weight was obtained by curing and crosslinking PUA at a certain temperature.

\subsection{Effect of reaction temperature on NCO content}

In this experiment, IPDI, CHO-THF co-polyether, HEMA, etc. were selected as raw materials, whose ratio was set to $3: 1: 3$, while the quality of DBTL is $0.2 \%$ of that of the polyether, and a series of PUAs were prepared at different polymerization temperatures by pre-polymer method, and also the NCO content was measured every 10 minutes during the reaction. Fig. 3 show the effect of reaction temperature on $\mathrm{NCO}$ content.

It can be seen from Fig. 3 that, in pre-polymerization stage, the NCO content sharply decreased first and then tended to stability, and also the reduction rate of $\mathrm{NCO}$ content at $90{ }^{\circ} \mathrm{C}$ was faster than that of $70{ }^{\circ} \mathrm{C}$ and $50{ }^{\circ} \mathrm{C}$.
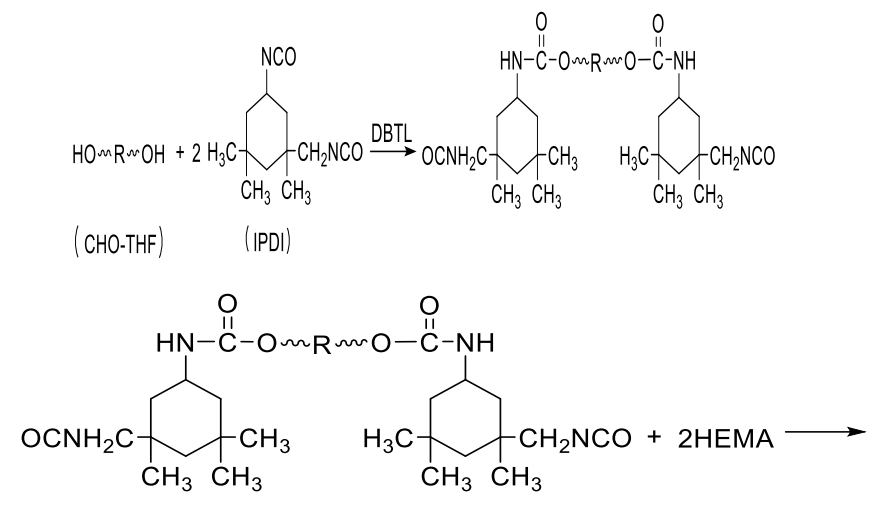

(PUA)
$\mathrm{CH}_{3}$

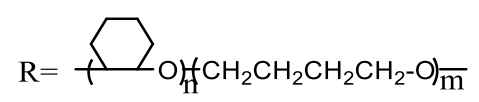

$\mathrm{HEMA}=\mathrm{H}_{3} \mathrm{C} \prod_{\mathrm{CH}_{2}}^{\mathrm{OH}} \sim \mathrm{OH}$

Fig. 1. Synthesis of epoxy cyclohexane-based macro-monomer

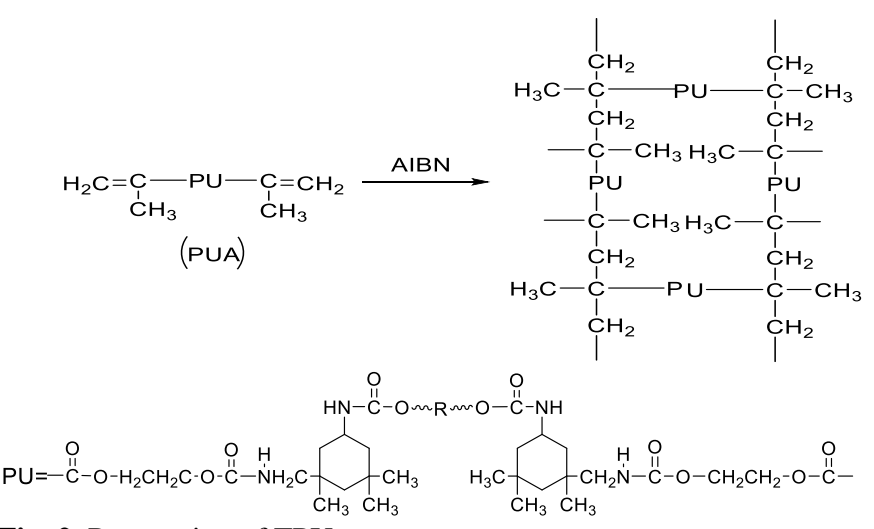

Fig. 2. Preparation of TPU

As can be seen from Fig. 4, in chain extension stage the reduction, rate of $\mathrm{NCO}$ content was lower than that in the pre-polymerization stage. NCO content was basically stable after about 50 minutes in the pre-polymerization process, however, which was stable after about 40 minutes at $75^{\circ} \mathrm{C}$ and 60 minutes at $50{ }^{\circ} \mathrm{C}$ in the polymerization process. Because of the fact that the reactivity of two NCO groups in IPDI is different, NCO group attached to the six-membered ring is more active, so NCO content is rapidly stabilized in the pre-polymerization stage, while the activity of another NCO group is reduced due to substituent group steric hindrance effect, which takes longer for NCO content to fall to stability compared with the former.

Although raising the reaction temperature is conducive to accelerating rate of polymerization, if the temperature is too high, the heat released in reaction is much faster and hard to remove, which leads to explosive polymerization and color of polymer deepened. Therefore, considering the 
rate of polymerization and the transparency of the polyurethane material, the reaction temperature in the prepolymerization stage was selected to be $90{ }^{\circ} \mathrm{C}$, while the optimum temperature in the chain extension stage was $75^{\circ} \mathrm{C}$.

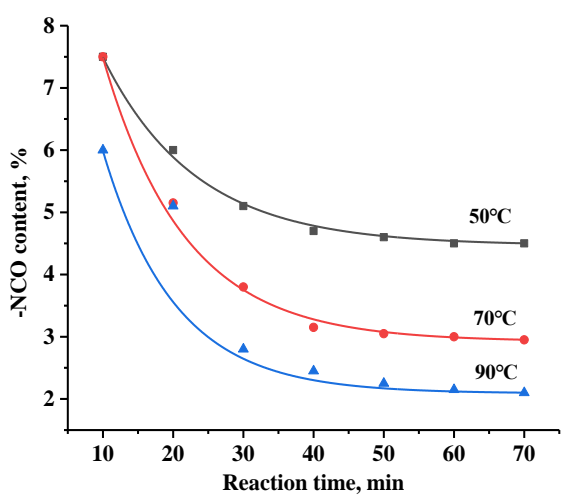

Fig. 3. Change of $-\mathrm{NCO}$ content in pre-polymerization stage

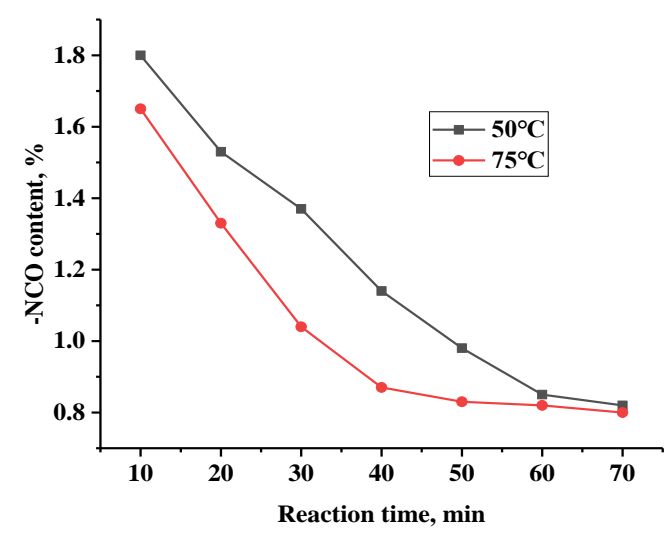

Fig. 4. Variation of $-\mathrm{NCO}$ content in chain extension stage

\subsection{Effect of catalyst dosage on NCO content}

Catalyst can reduce the activation energy, accelerate the reaction rate, shorten the reaction time and control the side reaction. In general, organometallic catalysts have high catalytic selectivity and catalytic efficiency for the reaction of isocyanates with hydroxyl groups (so-called gelation reaction) [12]. Therefore, DBTL was selected as catalyst of polymerization in this experiment. The recognized catalytic mechanism is based on the attack of nucleophilic agents on isocyanates to form intermediate complexes and then react with hydroxyl compounds according to Eq. 2 and Eq. 3 [13].

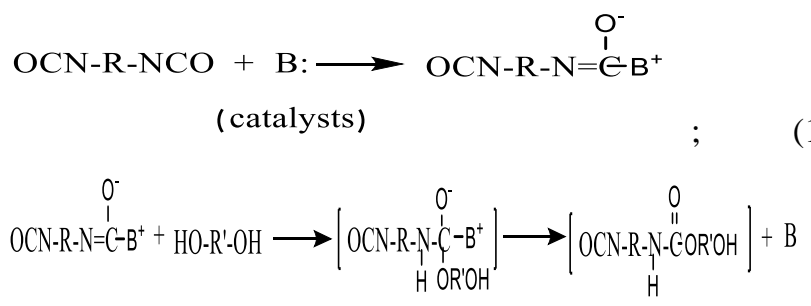

In this experiment, the effect of catalyst dosage on the NCO content in the polymerization was studied. The experimental results were shown in Table 1, which showed that the more DBTL was added, the less NCO content was left in the reaction mixture. When catalyst dosage reached
$0.2 \%$, the reaction between $-\mathrm{NCO}$ and $-\mathrm{OH}$ was almost completed. Therefore, the optimum addition of DBTL was selected to be $0.2 \%$ of quality of polyether.

Table 1. Effect of catalyst dosage on NCO content

\begin{tabular}{|c|c|c|c|}
\hline Sample & 1 & 2 & 3 \\
\hline Catalyst dosage & 0.1 & 0.15 & 0.2 \\
\hline NCO content & 1.25 & 0.78 & 0.35 \\
\hline
\end{tabular}

\subsection{Effect of curing parameter $R$ on oroperties of polyurethane materials}

Curing parameter $R$ refers to the molar ratio of $-\mathrm{NCO}$ in isocyanate to $-\mathrm{OH}$ in polyether, that is, the relative content of soft and hard segments of polyurethane [14, 15]. In this paper, the ratio of HEMA to IPDI is fixed at $1: 1$, and the effect of curing parameter $R$ on transparency and mechanical properties of TPU is analysed. It can be seen from Fig. 5 that the polyurethanes prepared by different $R$ values have good light transmittance, and the change of $R$ value has little effect on transparency of materials, which is because the CHO-THF co-polyether is a flexible chain segment, whose molecular structure is disordered, which is hard to crystallize. At the same time, the cross-linked network structure inside the polyurethane material prevents the micro-phase separation between the soft and hard segments to a certain extent, which destroys the crystal structure of the molecules, thereby enhancing the light transmittance.

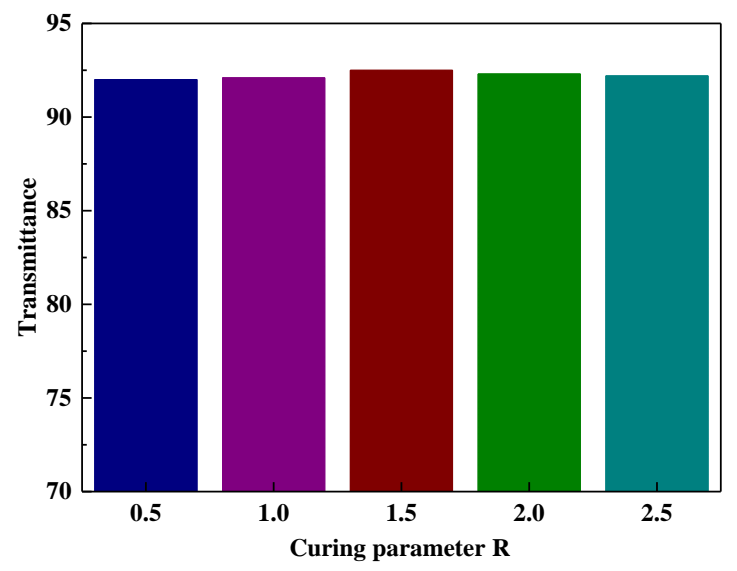

Fig. 5. Effect of curing parameter $R$ on transparency of polyurethane materials

The effect of curing parameter $R$ value on the mechanical properties of polyurethane materials is shown in Table. 2. It can be seen from the graph that, in a certain range, the shore hardness and tensile strength of TPU increase in different degrees with the increase of curing parameter $R$, while the impact resistance decreases continuously. This is mainly because the increase of the $R$ value will increase the hard segment content of the polymer, the hydrogen bonding effect is strengthened and the physical crosslinking point is increased, thereby increasing the tensile properties and the shore hardness. Theoretically, when $R=1$, the molecular weight is the largest, and the comprehensive properties of the material are the best. Table 2 shows that when $R=1.5$, the comprehensive properties of the material are the best. When $R>1.5$, excessive $\mathrm{NCO}$ will further react with carbamate or active 
hydrogen in substituted urea to form cross-linking bonds such as urea carbamate or biuret. The formation of a small amount of cross-linking bonds has a great contribution to improving the strength and other properties of polyurethane materials, but too much isocyanate will produce too much chemical cross-linking, which is not conducive to the mechanical properties of polyurethane materials.

Table 2. Effect of curing parameter $R$ on mechanical properties of polyurethane materials

\begin{tabular}{|c|c|c|c|}
\hline$R$ value & $\begin{array}{c}\text { Shore } \\
\text { hardness, } \mathrm{A}\end{array}$ & $\begin{array}{c}\text { Tensile strength, } \\
\mathrm{MPa}\end{array}$ & $\begin{array}{c}\text { Impact strength, } \\
\mathrm{kJ} / \mathrm{m}^{2}\end{array}$ \\
\hline 0.5 & 49 & 0.19 & 1.13 \\
\hline 1 & 60 & 1.62 & 2.93 \\
\hline 1.5 & 67 & 4.56 & 2.70 \\
\hline 2 & 70 & 1.70 & 2.29 \\
\hline 2.5 & 56 & 1.08 & 2.08 \\
\hline
\end{tabular}

\subsection{FTIR analysis}

FTIR spectra of the CHO-THF co-polyether is showed in Fig. 6. As can be seen from the figure that the characteristic absorption peaks of ether bond $(\mathrm{C}-\mathrm{O}-\mathrm{C})$ are at $1088 \mathrm{~cm}^{-1}$, while the vibration absorption peaks of hydroxyl $(-\mathrm{OH})$ are at $3438 \mathrm{~cm}^{-1}$, and the $\mathrm{C}-\mathrm{H}$ stretching vibration peaks of methylene $\left(-\mathrm{CH}_{2}\right)$ and methylene $(-\mathrm{CH})$ are at $2929 \mathrm{~cm}^{-1}$ and $2855 \mathrm{~cm}^{-1}$ respectively and the deformation vibration of $\mathrm{C}-\mathrm{H}$ is at $1448 \mathrm{~cm}^{-1}$, which proves that the ring-opening polymerization of $\mathrm{CHO}$ and THF is realized and hydroxyl-terminated co-polyether is formed.

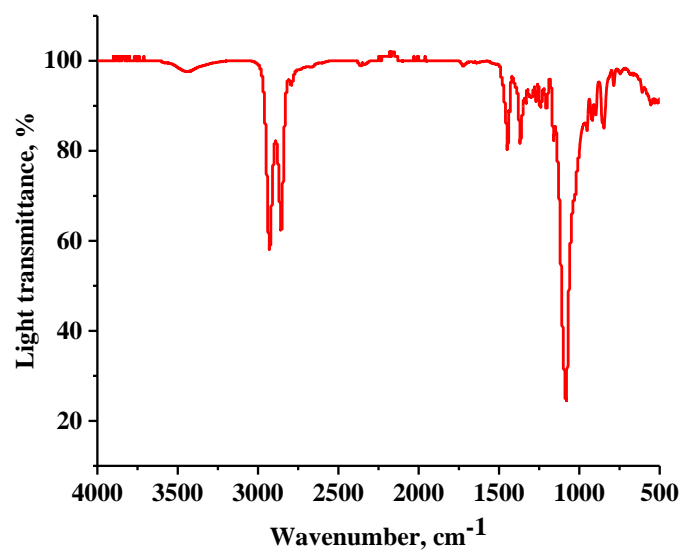

Fig. 6. FTIR spectra of CHO-THF co-polyether

It can be seen from Fig. 7 that, compared with Fig. 6, curve (1) does not exhibit a vibrational absorption peak of $-\mathrm{NCO}$ at $2254 \mathrm{~cm}^{-1}$, indicating that $-\mathrm{NCO}$ has reacted with CHO-THF copolymer ether and -OH in HEMA completely. In curve (1), bending vibration absorption kurtosis of secondary amide $(-\mathrm{NH})$ is observed at $1532 \mathrm{~cm}^{-1}$, and the characteristic absorption peak of carbonyl group $(\mathrm{C}=\mathrm{O})$ of carbamate is observed at $1518 \mathrm{~cm}^{-1}$, which indicates that synthetic PUA contains $-\mathrm{N}-\mathrm{C}=0$, which is an important characteristic of judging polyurethane. Curve (1) exhibited a characteristic absorption peak of $-\mathrm{C}=\mathrm{C}-$ at $1718 \mathrm{~cm}^{-1}$, whereas curve (2) exhibited a significant decrease in peak strength, indicating that $-\mathrm{C}=\mathrm{C}-$ in PUA did undergo curing and crosslinking to obtain TPU with larger molecular weight.

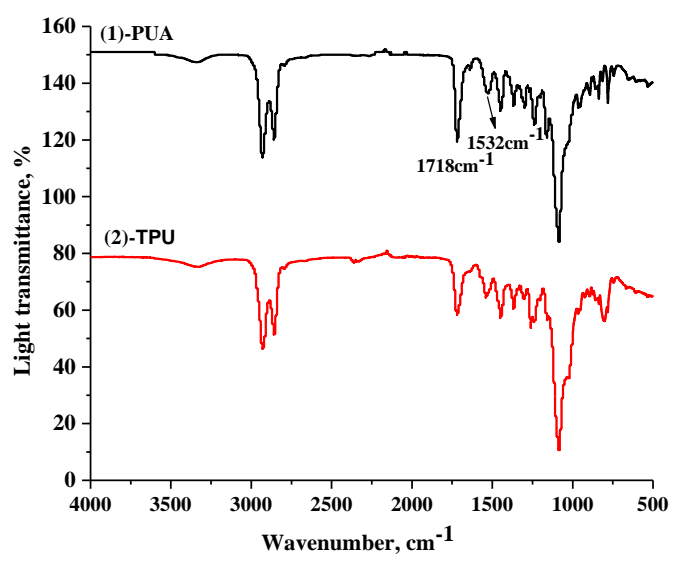

Fig. 7. FTIR spectra of PUA (1) and TPU (2)

\section{6. ${ }^{1} \mathrm{H}$ NMR analysis}

The ${ }^{1} \mathrm{H}$ NMR spectrum of CHO-THF co-polyether is presented in Fig. 8. It can be seen from Fig. 8 that the absorption peaks between $\delta 1.0$ and $\delta 2.0$ are proton peaks on the carbon not adjacent to oxygen in the residual cyclohexane oxide and those on the carbon not connected to oxygen in the THF segment $\left(-\mathrm{OCH}_{2} \mathrm{CH}_{2} \mathrm{CH}_{2} \mathrm{CH}_{2} \mathrm{O}-\right)$; the absorption peaks between $\delta 3.0$ and $\delta 4.0$ are proton peaks on the carbon linked to oxygen in the monomer residue; the proton peak at $\delta 3.1$ is hydroxyl-terminated, and the strength of the peak is very weak due to the small number of hydroxyl-terminated proton peaks; the solvent peak at $\delta 7.26$.

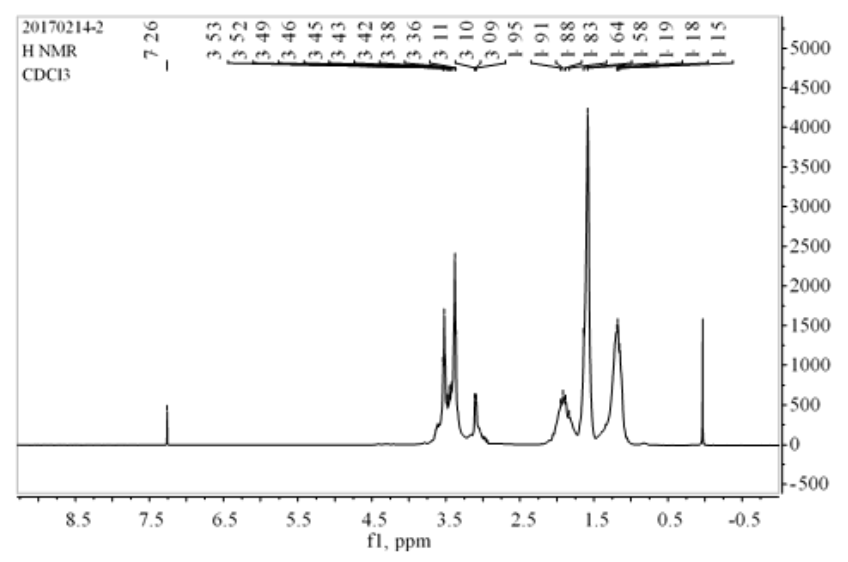

Fig. 8. ${ }^{1} \mathrm{H}$ NMR spectrum of CHO-THF co-polyether

\subsection{Thermal analysis of polyurethane material}

It can be concluded from Fig. 9 that the epoxy cyclohexane-based transparent polyurethane material has almost no thermal decomposition before $330{ }^{\circ} \mathrm{C}$, indicating that the thermal properties are relatively stable. When the temperature continues to increase, there are two peaks of weightlessness, the first is between $330{ }^{\circ} \mathrm{C}$ and $380^{\circ} \mathrm{C}$, and the second is between $380{ }^{\circ} \mathrm{C}$ and $413{ }^{\circ} \mathrm{C}$. This is mainly because the thermal decomposition process of epoxy cyclohexane-based transparent polyurethane material is divided into two stages, the first stage is the thermal decomposition of hard segment in polyurethane, and the second stage is the thermal decomposition of soft segment co-polyether. It can be seen that the epoxy cyclohexanebased transparent polyurethane material has a high thermal 
decomposition temperature and good heat resistance stability.

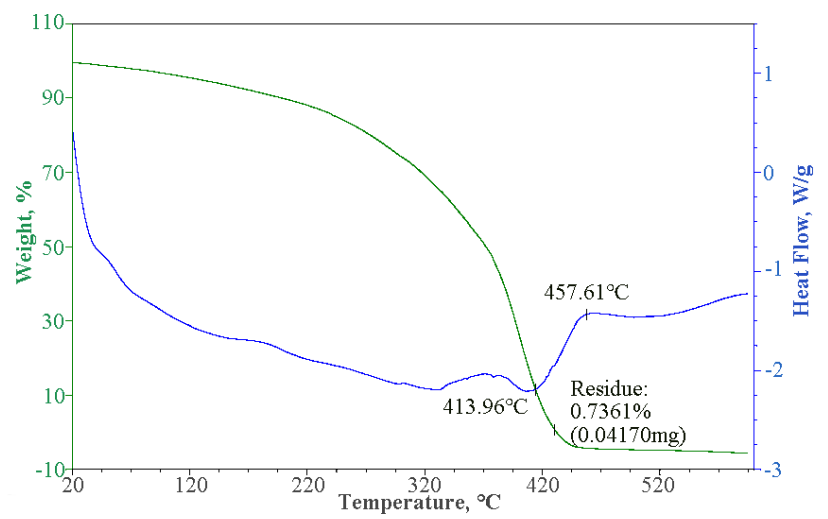

Fig. 9. DSC-TGA curve of epoxy cyclohexane-based transparent polyurethane material

\section{CONCLUSIONS}

PUA was synthesized from CHO-THF co-polyether. The following conclusions were drawn: The synthesis conditions are as follows: the amount of catalyst (DBTL) is $0.2 \%$ of the mass of polyether; the reaction temperature in the pre-polymerization stage is $90{ }^{\circ} \mathrm{C}$ and the reaction time is $50 \mathrm{~min}$; the reaction temperature in the chain extension stage is $75^{\circ} \mathrm{C}$ and the reaction time is $40 \mathrm{~min}$. With the increase of the $\mathrm{R}$ value of the curing parameter, the Shore hardness and tensile strength of the TPU material are continuously enhanced, the impact resistance is continuously reduced and the light transmittance is basically unchanged.

\section{REFERENCES}

1. Zhang, L.H., Yao, X.H., Zang, S.G., Gu, Y.B. Temperature and Strain Rate-Dependent Constitutive Modeling of the Large Deformation Behavior of a Transparent Polyurethane Interlayer Polymer Engineering \& Science $55(8)$ 2015: pp. $1864-1872$.

https://doi.org/ 10.1002/pen.24026

2. Paserb, M.A., Bakirova, I.N., Valuev, V.I. New Aromatic Oligoesters and Their Use in the Synthesis of Heat-Resistant Polyurethane Coatings Russian Journal of Applied Chemistry 87 (3) 2013: pp. 303-306. https://doi.org/10.1134/S1070427214030100

3. Chen, W.Y., Guang, J.G. Heat Resistance Properties of an Cured ATPU/Epoxy Resin Advanced Materials Research
1058 2014: pp. $127-131$.

https://doi.org/10.4028/www.scientific.net/AMR.1058.127

4. Zhang, L.H., Yao, X.H., Zang, S.G., Han, Q. Temperature and Strain Rate Dependent Tensile Behavior of a Transparent Polyurethane Interlayer Materials \& Design $65(10)$ 2015: pp. $1181-1188$. https://doi.org/ 10.1016/j.matdes.2014.08.054

5. Zhang, J., Tu, W., Dai, Z. Transparent Polyester PolyolBased Polyurethane Coatings: the Effect of Alcohols Journal of Coatings Technology and Research 10 (6) 2013: pp. 887-895. https://doi.org/10.1007/s11998-013-9527-x

6. Lan, L.W. Polymer Physics, Northwest Polytechnic University Press, Shanxi. 1985: pp. $25-41$.

7. Xie, H.Q., Liu, Z.H., Liu, H., Guo, J.S. Nonlinear Optical Crosslinked Polymers and Interpenetrating Polymer Networks Containing azo-Benzothiazole Chromophore Groups Polymer 39 (12) 1998: pp. 2393-2398. https://doi.org/10.1016/S0032-3861(97)00537-5

8. GB/T 12008.3-1989. Polyether Polyols-Determination of Hydroxyl Number Beijing: China Standard Press 1989.

9. GB/T 2411-2008. Plastics and Ebonite-Determination of Indentation Hardness by Means of Duronmeter(Shore Hardness) Beijing:China Standard Press 2008.

10. GB/T 1040.1-2006. Plastics-Determination of Tensile Properties Beijing: China Standard Press 2006.

11. GB/T 1843-2008. Plastic- Determination of izod impact strengeth Beijing: China Standard Press 2008.

12. Blank, W.J., He, Z.A., Hessell, E.T. Catalysis of the Isocyanate-Hydroxyl Reaction by Non-Tin Catalysts Progress in Organic Coatings 35 (1) 1999: pp. 19-29. https://doi.org/10.1016/S0300-9440(99)00006-5

13. Reegen, S.L., Frisch, K.C. Isocyanate-Catalyst and Hydroxyl-Catalyst Complex Formation Journal of Polymer Science Part A-1: Polymer Chemistry 8 (10) 1970: pp. $2883-2891$. https://doi.org/10.1002/pol.1970.150081014

14. Zhang, J., Tu, W., Dai, Z. Synthesis and Characterization of Transparent and High Impact Resistance Polyurethane Coatings Based on Polyester Polyols and Isocyanate Trimers Progress in Organic Coatings 75 (4) 2012: pp. 579-583. https://doi.org/10.1016/j.porgcoat.2012.05.005

15. Zhang, J., Tu, W., Dai, Z. Synthesis and Microstructure of High Performance Transparent Polyurethane Films Polymeric Materials Science and Engineering $29(11)$ 2013: pp. $119-123$. https://doi.org/10.1002/pen.23305 